\title{
Selective attention in visual recognition with pictorial and verbal alternatives
}

\author{
GORDON M. REDDING, WILLIAM M. SEWARD, and DEAN E. STOLLDORF \\ Illinois State University, Normal, Ilinois 61761
}

\begin{abstract}
Recognition accuracy for tachistoscopically presented pictures of common objects was tested for independent groups of subjects who performed under factorial combinations of pictorial or verbal, similar or dissimilar alternatives, which were presented either before and after or only after test pictures. For both verbal and pictorial alternatives, recognition was less with similar than with dissimilar alternatives, the difference being greatest in the only-after condition, and performance with dissimilar alternatives was relatively unaffected by the time at which alternatives were presented. Although the pattern of results was similar, recognition was generally poorer with verbal than with pictorial alternatives. Results are interpreted in terms of pictorial recoding of verbal information, such that for both pictorial and verbal alternatives a set of critical features may be identified which distinguish among the alternatives, and which guide selective perceptual processing of a following pictorial target.
\end{abstract}

Instructional set effects have been known at least since the time of Kulpe's (1904) and Chapman's (1932) experiments, and subsequent research has largely been directed toward determining the nature of such attentional selection. For example, Lawrence and Coles (1954) tachistoscopically presented single pictures of common objects for recognition, with sets of four single-word alternatives, similar or dissimilar (discrete), presented either before or after the target. Recognition did not benefit from alternatives presented before the taiget, nor did the discriminability of alternatives have a reduced effect in the before cue condition, as would be expected if selection occurred in perceptual processing. Moreover, since performance was poorer when no alternatives were presented, Lawrence and Coles concluded that selective attention has its locus in postperceptual processes.

More recently, Egeth and Smith (1967) noted that the single-word verbal labels used by Lawrence and Coles did not actually provide the opportunity for perceptual selection, since subjects could not readily extract a set of critical visual features which would reliably distinguish among the four classes of objects named by the alternatives. Egeth and Smith, therefore, repeated the Lawrence and Coles study using similar or dissimilar pictorial alternatives, presented either after only or before and after the pictorial target. ${ }^{1}$ With these modifications, Egeth and Smith found both a main effect of cue condition and the predicted interaction of Cue Condition by Type of Alternative. Recognition with

A preliminary report of this study appeared as a paper read at meetings of the Midwestern Psychological Association, Chicago, Illinois, May 1976. The authors wish to thank Elizabeth R. Erspamer and Miles A. Lombard for their assistance in consstructing stimulus materials and in pilot work done for the present experiment. Requests for reprints should be sent to Gordon M. Redding, Department of Psychology, Illinois State University, Normal, Illinois 61761 . similar alternatives was poorer, relative to dissimilar alternatives, in the after-only than in the before-andafter cue condition, and performance with dissimilar alternatives was relatively unaffected by cue condition.

These data suggest that selective perceptual processing is possible whenever alternatives prior to the stimulus are discriminable in terms of visual features. However, there is no reason to believe that the alternatives must be pictorial. Posner (1970; Posner \& Warren, 1972) and others (e.g., Klatzky, 1972) have demonstrated dual coding of visual stimuli, and Tversky (1969) has shown that both verbal and pictorial stimuli may be interchangeably coded, either verbally or pictorially, depending upon the demands of the task. These observations suggest the possibility of perceptual selection with verbal alternatives. If verbal alternatives are constructed such that they convey pictorial differences among the alternatives, subjects may be able to pictorially recode the verbal information and selectively process a subsequent pictorial target for critical features.

The present experiment was designed to test this possibility. Egeth and Smith's (1967) procedure was used, but in different conditions the same target pictures were presented with pictorial and verbal alternatives. Verbal alternatives were short phrases, selected to describe critical features of the pictorial alternatives. If critical features were included in verbal descriptions and the information efficiently encoded, it was expected that evidence of selection with verbal alternatives should approach that found with pictorial alternatives.

\section{METHOD}

\footnotetext{
Design

Eight groups of 16 subjects each were run, treatment for each group being defined by factorial combination of three variables: time of cue (before and after vs. after only), alternatives similarity (similar vs. dissimilar), and type of alternatives (pictorial vs. verbal). Four different random orders of presentation of 20 test
} 
Table 1

Mean and Standard Deviation of Number of Correct Responses on 20 Trials as a Function of Mode of Alternative Presentation, Time of Presentation of Alternatives, and Similarity of Alternatives

\begin{tabular}{lccccc}
\hline & \multicolumn{2}{c}{$\begin{array}{c}\text { Verbal } \\
\text { Alternatives }\end{array}$} & & \multicolumn{2}{c}{$\begin{array}{c}\text { Pictorial } \\
\text { Alternatives }\end{array}$} \\
\cline { 2 - 3 } \cline { 6 - 6 } & $\begin{array}{c}\text { Before and } \\
\text { After }\end{array}$ & $\begin{array}{c}\text { After } \\
\text { Only }\end{array}$ & $\begin{array}{c}\text { Before and } \\
\text { After }\end{array}$ & $\begin{array}{c}\text { After } \\
\text { Only }\end{array}$ \\
\hline Dissimilar & 13.25 & 11.69 & & 17.94 & 18.06 \\
Alternatives & $(1.98)$ & $(1.89)$ & & $(1.39)$ & $(1.84)$ \\
Similar & 10.19 & 7.75 & & 15.06 & 7.88 \\
Alternatives & $(1.97)$ & $(1.57)$ & & $(2.24)$ & $(1.54)$ \\
\hline
\end{tabular}

Note-Standard deviations are in parentheses.

pictures were used within each treatment combination, with four subjects in each group receiving the same order. Subjects were female students who volunteered in return for course credit.

\section{Apparatus}

Test pictures were displayed for $20 \mathrm{msec}$ in an Iconix fourfield tachistoscope, only two fields of which were utilized. In an effort to stop processing and reduce afterimage persistence, the adapting field consisted of a pattern mask constructed from small bits and pieces of test pictures, with a small fixation cross centered in the field. Test pictures were irregular in shape, averaging $5.8 \mathrm{~cm}$ wide $\times 5.7 \mathrm{~cm}$ high (approximately 3.6 degrees visual angle). Total mask area was approximately $10 \times 10 \mathrm{~cm}$ (6.4 degrees).

\section{Procedure}

Following five practice trials, 20 experimental trials were given, one for each of 20 test pictures. On before-and-after trials, the subject was shown a plaque of four alternatives which she examined for $20 \mathrm{sec}$. The subject then looked into the tachistoscope, fixated the black cross, and a target was presented. After target presentation, the subject looked back to the plaque of alternatives and pointed to the picture or verbal description which she believed had been presented. A maximum of $20 \mathrm{sec}$ was allowed for response, and subjects were required to respond even if uncertain. In after-only conditions, the subject waited for a signal, and after she was looking into the tachistoscope, a plaque of alternatives was slipped into place. In all other respects the after-only and before-and-after conditions were identical.

\section{Stimuli}

Stimuli for pictorial alternatives were assembled from pictures of objects found in mail-order catalogs and magazines. Selections were cut out and several photographic copies were made using fine-grain black-and-white film. In pictorial similar conditions, the four alternatives were pictures of similar instances of the same type of object, e.g., four different types of cooking pots. Twenty-five sets of four alternatives were selected in this manner, and each set was arranged in a square matrix, mounted on an 8 -in. $(20.32-\mathrm{cm})$ square of white posterboard. Test pictures appeared equally often in each of the four positions on the plaque. In dissimilar conditions, the 25 test pictures were paired with alternatives produced by recombining the photographs such that all four alternatives were pictures of different objects.

The same set of 25 test pictures was used in verbal alternatives conditions, together with verbal descriptions of the corresponding sets of pictorial alternatives, e.g., "decorated pot," "shiny pot," "light pot," "dark pot." Verbal descriptions (two to four words in length) were selected by four judges, typewritten, and attached to plaques in the same relative position as their photographic correlates. In all other respects the stimulus materials in the various conditions were identical.

\section{RESULTS}

Table 1 shows the mean number of correct responses for the various combinations of variables. Analysis of variance indicated significance (at least $p<.025$ ) for all main and interaction effects. Therefore, a NewmanKuels test was performed $(p<.01)$ to test for differences among means. With pictorial dissimilar alternatives, performance was high, with no significant difference between cue conditions; however, performance was lower with similar alternatives, the difference being greatest when the alternatives were presented only after the test picture. Performance was poorer with verbal alternatives, but the pattern is similar. Recognition for dissimilar alternatives is superior to that for similar alternatives, in both cue conditions; however, the decrease in the after-only condition is significant only for similar alternatives. The difference between cue conditions for dissimilar alternatives was not significant, and is due in part to one subject who performed poorly.

\section{DISCUSSION}

These results indicate that perceptual selection is possible with both visual and verbal alternatives, if the available information allows discrimination among the alternatives. One interpretation is that subjects were able to pictorially encode verbal alternatives such that, for both pictorial and verbal alternatives, they could identify a set of critical features which distinguished among the alternatives. Analysis of a following target could then be restricted to these features, thereby facilitating recognition of the briefly presented target picture. On the other hand, when alternatives are presented only after the target, the subject must rely on her relatively crude memory of the target. Performance based on the unselected memory trace was as efficient as perceptual selection when the alternatives were easily discriminable; however, the memory trace was inadequate when the alternatives were similar.

The similarity in pattern of results for pictorial and verbal alternatives supports the idea of similar selection mechanisms, but the generally poorer performance with verbal alternatives requires further explanation. Selectivity in processing with verbal alternatives may be less efficient for two reasons: First, despite efforts to include distinguishing features, the verbal descriptions may not have provided as much critical information as did the pictorial alternatives. Second, the information available with verbal alternatives may have been less efficiently encoded, more abstracted, and more lacking in detail than with pictorial alternatives. Experiments are underway which should allow assessment of the relative contribution of encoding efficiency and stimulus sufficiency in selection based on verbal cues, and which will further test the hypothesis that similar and selective perceptual processes are involved for both verbal and pictorial alternatives.

\section{REFERENCES}

Chapman, D. W. Relative effects of determinate and indeterminate Aufgaben. American Journal of Psychology, 1932, 44, 163-174. 
Egeth, H. \& Smith, E. E. Perceptual selectivity in a visual recognition task. Journal of Experimental Psychology, 1967, 74, 543-549.

KLATZKY, R. L. Visual and verbal coding of laterally presented pictures. Journal of Experimental Psychology, 1972, 96, 439-448.

KüLPE, O. Versuche uber Abstraktion. Berlin International Congress of Experimental Psychology, 1904, 56-68.

LAWRENCE, D. H., \& Coles, G. R. Accuracy of recognition with alternatives before and after the stimulus. Journal of Experimental Psychology, 1954, 47, 208-214.

Long, E. R.. Reid, L. S., \& Henneman, R. H. An experimental analysis of set: Variables influencing the identification of ambiguous, visual stimulus-objects. American Journal of Psychology, 1960, 73, 553-562.

PosNer. M. I. Abstraction and the process of recognition. In J. T. Spence \& G. H. Bower (Eds.), Advances in learning and motivation (Vol. 3). New York: Academic Press, 1970.
Posner, M. I., \& Warren, R. E. Traces, concepts, and conscious constructions. In A. W. Melton \& E. Martin (Eds.), Coding processes in human memory. Washington, D. C.: Winston, 1972.

TVERsky, B. Pictorial and verbal encoding in a short-term memory task. Perception \& Psychophysics, 1969, 6. 225-233.

\section{NOTE}

1. Egeth and Smith introduced the before-and-after modification to control for differences in memory load between cue conditions. See also Long, Reid, and Henneman (1960).

(Received for publication June 5, 1976.) 